\section{Guest editorial: Global energy transformation for combating climate change in the built environment: challenges and opportunities in developing countries}

Globally, buildings account for 30-40\% of total energy consumption (Peng et al., 2019; Dong et al., 2021) and are responsible for about one-third of greenhouse gas (GHG) emissions (Lam et al., 2014; Fenner et al., 2020). The use of conventional energy, mainly from fossil-fuel-based energy generation systems (Flammini et al., 2021), continue to be the major energy supply to buildings, thereby contributing significantly to global warming and climate change. With the signing of the Paris Agreement that sets out a global framework to avoid dangerous climate change by limiting global warming to well below $2 \mathrm{C}$ and pursuing efforts to limit it to $1.5 \mathrm{C}$ (Gunfaus and Waisman, 2021), it has become necessary to explore low-carbon energy transformation pathways in all sectors for climate change mitigation and adaptation (Zhao et al., 2021; Linton et al., 2021).

In the built environment, energy consumption is influenced by a number of factors including building design and materials used for the construction (Opoku et al., 2020), the occupancy rate, the type and efficiency of the appliances used in the building, as well as the behavior of the occupants using the building (Ahadzie et al., 2020). Researchers, practitioners and policy makers across the globe are therefore exploring opportunities to improve efficiency of energy systems, energy consumption behavior, smart technologies, carbon sink materials for building construction, etc. in order to reduce building energy consumption and emissions (Arrigoni et al., 2017).

Integration of renewable energy in buildings also brings opportunity to diversify building energy supply to low-carbon pathway, thereby reducing energy-related emissions during the operational phase of the building (Wang et al., 2021). Renewable energy for running HVAC systems which are the major energy consuming equipment in buildings has therefore been explored to reduce building energy consumption and emissions (Opoku et al., 2018).

Over the past decades, a lot of research have been conducted worldwide to explore the possible solutions for combating climate change in the built environment due to its negative impact on humanity and socio-economic development (Fathy et al., 2021; Nhep et al., 2021). Global energy transformation that prescribes sustainable energy supply with low-carbon renewable energy generation pathways coupled with energy efficiency presents opportunity for decarbonization and contributing to the target of limiting global warming to well below $2 \mathrm{C}$. While there are clear policies, technology innovations, initiatives and programs to realize some of these global targets in developed countries, not much is known for developing countries. From available literature, there are scanty information on specific technology innovations and programs, particularly in Africa, that support global energy transformation targets.

The aim of this special issue is therefore to understand the cutting-edge research and technologies being implemented in developing countries to achieve clean, affordable and

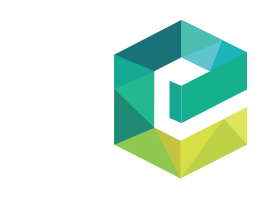

International Journal of Building Pathology and Adaptation Vol. 40 No. 2,2022 pp. $161-164$

(c) Emerald Publishing Limited 
IJBPA

40,2

sustainable energy for the built environment. In addition, efficient technologies that deliver effective thermal cooling of buildings in a sustainable manner to enhance significant energy efficiency improvements and reductions in GHG emissions to address SDG 13 are priority for this Special Issue.

International contributions to this special issue address the range and depth of current research on very interesting topics including smart technologies and energy efficiency, mechanical cooling and energy efficiency practices, indigenous technologies and community actions, renewable energy development for the built environment and energy consumption behavior in sub-Saharan economies. Research studies presented in this special issue with case studies from countries like South Africa, Ghana, Burkina Faso, Nigeria and Uganda present the generality of the challenges and opportunities in energy transformation for combating climate change in the built environment in developing countries, especially in Africa. The following section presents highlights from the seven papers published in this special issue.

Drawing on systematic review of the literature (SLR), aided by the PRISMA guiding principle, Simpeh et al. (2021) reviewed the status and current trends of energy consumption associated with HVAC systems with the aim of interrogating energy efficiency practices for improving HVAC energy consumption in buildings. The authors developed an integrated optimization conceptual framework, highlighting energy efficiency options that may complement HVAC systems operations in buildings.

The study presented by Ouedraogo et al. (2021) discussed the major challenges faced by West African countries in finding comfortable housing because of climate change and population growth. They proposed an adaptive model which relies on a combination of parameters such as the operative temperature, the new effective temperature and the basic parameters of thermal comfort. The decision-making tool proposed in their study based on bio-climatic concept through a long-term comfort index, allows building stakeholders to design, assess and improve the thermal environment of buildings better and easily, compared to conventional approaches.

Agyekum et al. (2021) presented a study on factors limiting the adoption of hemp as an alternative sustainable material for green building delivery in Ghana. They established that lack of awareness on the opportunities of low-embodied carbon building materials, like hemp, for green building delivery is the major factor for their adoption.

In the work of Jegede et al. (2021), they demonstrated the optimization of an existing residential building in a tropical climate using indigenous materials. The indigenous materials were used as alternative to conventional building envelopes to achieve thermal comfort and affordable housing in the city of Abuja, Nigeria. Using energy plus simulation tool in DesignBuilder, they demonstrated that the use of indigenous materials in buildings in Nigeria substantially reduced the annual operative temperature by $8 \%$, thereby increasing the predicted three months of thermal comfort in the base case to nine months annually, resulting in about one-third reduction in the annual $\mathrm{CO}_{2}$ emissions, cooling loads and construction costs.

Ekung et al. (2021) presented a study on green cost premium (GCP) for attaining energyefficiency rating in Nigeria's hot-humid residential buildings. Their study provided cost benchmarks for navigating cost planning and budgetary decisions during energy-efficient designs (ED) of buildings. They demonstrated that potential GCPs and their payback periods are actually less than feared and that less than 5 and $21 \%$ extra funding would be required to achieve 1 to 4-star and 5-star energy-efficiency ratings involving passive design interventions and photovoltaic systems.

The study by Frimpong et al. (2021) presented a new and simple model for the prediction of unregulated energy usage in buildings. A method for determining a set of optimum values of power and usage periods of unregulated energy loads (UEL) required by the model was 
developed. Their study showed that non-dominated sorting genetic algorithm II (NSGA-II) for predicting the energy consumption of UELs in offices is highly accurate and suitable for adoption by energy modelers, building designers and building regulatory agencies.

Finally, the study of Elasu et al. (2021) explored the economic and socio-demographic factors that influence households' decisions on the type of fuel used for cooking in urban areas in Uganda. Their study established that kitchen type, dwelling type and the type of apartment tenure significantly influence the choice of household cooking fuel decisions.

The seven papers presented in this special issue provide a valuable contribution to the discourse on climate change-resilient nexus by highlighting the challenges and opportunities in the global energy transformation for combating climate change in the built environment, particularly in developing countries.

\section{Richard Opoku \\ Department of Mechanical Engineering, Kwame Nkrumah University of Science and Technology, Kumasi, Ghana, and \\ Henry Mensah and Divine Kwaku Ahadzie Centre for Settlements Studies, Kwame Nkrumah University of Science and Technology, Kumasi, Ghana}

\section{References}

Ahadzie, D.K., Opoku, R., Opoku Ware, S.N. and Mensah, H. (2020), “Analysis of occupant behaviour in the use of air-conditioners in public buildings in developing countries: evidence from Ghana", International Journal of Building Pathology and Adaptation, Vol. 39 No. 2, pp. 259-282, doi: 10. 1108/IJBPA-01-2020-0001.

Arrigoni, A., Pelosato, R., Melià, P., Ruggieri, G., Sabbadini, S. and Dotelli, G. (2017), "Life cycle assessment of natural building materials: the role of carbonation, mixture components and transport in the environmental impacts of hempcrete blocks", Journal of Cleaner Production, Vol. 149, pp. 1051-1061, doi: 10.1016/j.jclepro.2017.02.161.

Dong, Z., Liu, J., Liu, B., Li, K. and Li, X. (2021), "Hourly energy consumption prediction of an office building based on ensemble learning and energy consumption pattern classification”, Energy and Buildings, Vol. 241, doi: 10.1016/j.enbuild.2021.110929.

Fathy, R., Nelson, C.A. and Barbieri, J.S. (2021), "Combating climate change in the clinic: cost-effective strategies to decrease the carbon footprint of outpatient dermatologic practice", International Journal of Women's Dermatology, Elsevier, Vol. 7 No. 1, pp. 107-111, doi: 10.1016/j.ijwd.2020. 05.015 .

Fenner, A.E., Kibert, C.J., Li, J., Razkenari, M.A., Hakim, H., Lu, X., Kouhirostami, M. and Sam, M. (2020), "Embodied, operation, and commuting emissions: a case study comparing the carbon hotspots of an educational building", Journal of Cleaner Production, Vol. 268, doi: 10.1016/j. jclepro.2020.122081.

Flammini, M.G., Prettico, G., Mazza, A. and Chicco, G. (2021), "Reducing fossil fuel-based generation: impact on wholesale electricity market prices in the North-Italy bidding zone", Electric Power Systems Research, Vol. 194, doi: 10.1016/j.epsr.2021.107095.

Gunfaus, M.T. and Waisman, H. (2021), "Assessing the adequacy of the global response to the Paris Agreement: toward a full appraisal of climate ambition and action", Earth System Governance, Vol. 8, p. 100102, doi: 10.1016/j.esg.2021.100102.

Lam, P.T.I., Chan, E.H.W., Yu, A.T.W., Cam, W.C.N. and Yu, J.S. (2014), "Mitigating climate change in the building sector: integrating the unique characteristics of built facilities with emissions trading schemes”, Facilities, Vol. 32 Nos 7-8, pp. 342-364, doi: 10.1108/F-04-2013-0035. 
IJBPA

40,2

164
Linton, S., Clarke, A. and Tozer, L. (2021), "Technical pathways to deep decarbonization in cities: eight best practice case studies of transformational climate mitigation”, Energy Research and Social Science, Vol. 86, p. 102422, doi: 10.1016/j.erss.2021.102422.

Nhep, T., Schott, C. and Sahli, M. (2021), "Climate change adaptation in Cambodia's coastal hotel sector: an analysis of adaptation measures and hotel characteristics", Tourism Management Perspectives, Vol. 40, p. 100890, doi: 10.1016/j.tmp.2021.100890.

Opoku, R., Mensah-Darkwa, K. and Samed Muntaka, A. (2018), "Techno-economic analysis of a hybrid solar PV-grid powered air-conditioner for daytime office use in hot humid climates - a case study in Kumasi city, Ghana”, Solar Energy, Vol. 165, pp. 65-74, doi: 10.1016/j.solener.2018. 03.013.

Opoku, R., Obeng, G.Y., Darkwa, J. and Kwofie, S. (2020), "Minimizing heat transmission loads and improving energy efficiency of building envelopes in sub-Saharan Africa using bio-based composite materials", Scientific African, Vol. 8, doi: 10.1016/j.sciaf.2020.e00358.

Peng, Z., Deng, W. and Hong, Y. (2019), "Materials consumption, indoor thermal comfort and associated energy flows of urban residential buildings: case studies from the cold climate zone of China”, International Journal of Building Pathology and Adaptation, Vol. 37 No. 5, pp. 579-596, doi: 10.1108/IJBPA-01-2019-0007.

Wang, Y., Quan, Z., Jing, H., Wang, L. and Zhao, Y. (2021), "Performance and operation strategy optimization of a new dual-source building energy supply system with heat pumps and energy storage", Energy Conversion and Management, Vol. 239, doi: 10.1016/j.enconman.2021.114204.

Zhao, G., Yu, B., An, R., Wu, Y. and Zhao, Z. (2021), "Energy system transformations and carbon emission mitigation for China to achieve global $2{ }^{\circ} \mathrm{C}$ climate target", Journal of Environmental Management, Vol. 292, doi: 10.1016/j.jenvman.2021.112721. 